\title{
Measurements of the Atmospheric Electricity with Captive Balloon
}

\author{
By K. Uchikawa \\ Momambetsu Magnetic Observatory \\ and \\ G. Kondo \\ Honjo Aerological Observatory \\ (Manuscript received 18 September, 1954)
}

\begin{abstract}
Measurements of the electrical current in the mooring wire of the captive balloon and of the electrical conductivity in the lower atmosphere were carried out from January to October, 1953 at Honjo, Saitama-Prefecture. We observed these two elements in the fair weather nights.

The meteorological phenomena in calm days have been considered to have smaller influence on the atmospheric electricity. But from our results, it is considered that the potential gradients at the ground surface are remarkably affected by the meteorological phenomena-nocturnal inversions-in caim nights.
\end{abstract}

\section{概 要}

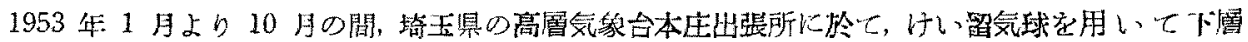
大気中の空中電気の测定を行つた。测定した要素は索電流 (主として尖端放電々流) 及び伝導度で

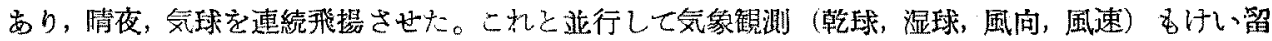

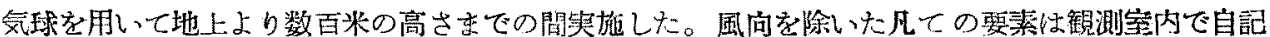
せしめた。䒺電流及び伝導度湘定に结真空管電位計を，温度湘定には棒状けーミスターを，風速の测 定にはビード型サーミスターを便用した。一方地上の電位傾度はー゚ンドルフ電位計を用いて記録さ せた。

その結果，夜間の気温の接地逆䎐の上部に索電流の最大值が現われ，これが地上の電位傾度の最大 值と対応している。気温の接地逆䎐の存在していないときは, 伝導度は地上より百数十米まで変化が 余りないが，逆䎐が存在しているときは，その上部で伝尊殷が減少している。

以上の事柄より逆䎐層の上部に正の空間電荷の存在汃推定ざれ，その毛度は計算によると 0.1 $\mathrm{ESU} / \mathrm{m}^{3}$ 程度である。静稳日に於ける気象現象性空中電気に及济す影留は少いとされていたが，吾

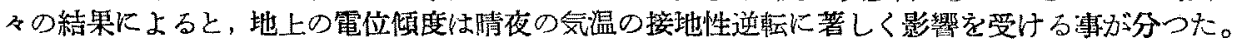

\section{§1. Introduction}

The observations of the atmospheric electricity in the lower atmosphere were performed with the captive balloons by $\mathrm{D}$. Nukiyama $^{(1)}, H$. Hatakeyama(2) and T. Kitaoka(3) in Japan. In Germany, the currents in the mooring wire were measured through two years using captive balloons or kites at Aerological Observatory, Lindenberg( ${ }^{(t)}$.

From these results, it was found that the meteorological phenomena in the lower atmosphere have much influence on the atmospheric potential gradient at the earth's surface. However, all these measurements were carried out in daytime, and they could not discuss on the diurnal variations of the atmospheric electricity.

We improved the method of measurements, and continuously made the balloons fly in fair weather night, in which the turbulent phenomena were remarkably less than in day. time.

The current flowing through the mooring wire and the electrical conductivity of the lower atmosphere were measured, and the potential gradient at the earth's surface was recorded with the Benndorf's electrometer. On the other hand, dry- and wet-bulb temperatures and wind velocity were measured simultaneously from the earth's surface to the altitude of some hundred metres. As the meteorological instruments rod-type thermistors and bead-type thermistors were used for temperature and wind velocity measurements respectively, and each element was recorded in the observation hut. 


\section{§ 2. Method of observation}

In our observations two captive balloons were used. One of them consisted of a bladder (inside) and nylon cloth and its volume was $2.4 \mathrm{~m}^{3}$, and the other was made of rubbercoating silk and its volume was $10 \mathrm{~m}^{3}$. The buoyancy of the former which was used for the measurements of the current was about $1 \mathrm{~kg}$, and that of the latter for the measurements of the conductivity was about $4 \mathrm{~kg}$.

The mooring wire consisted of four twisted and mutually insulated steel wires. Polyethylene tubes were used as the insulator. The whole diameter of the mooring wire was $5 \mathrm{~mm}$.

(1) Measurement of the current flowing through the mooring wire

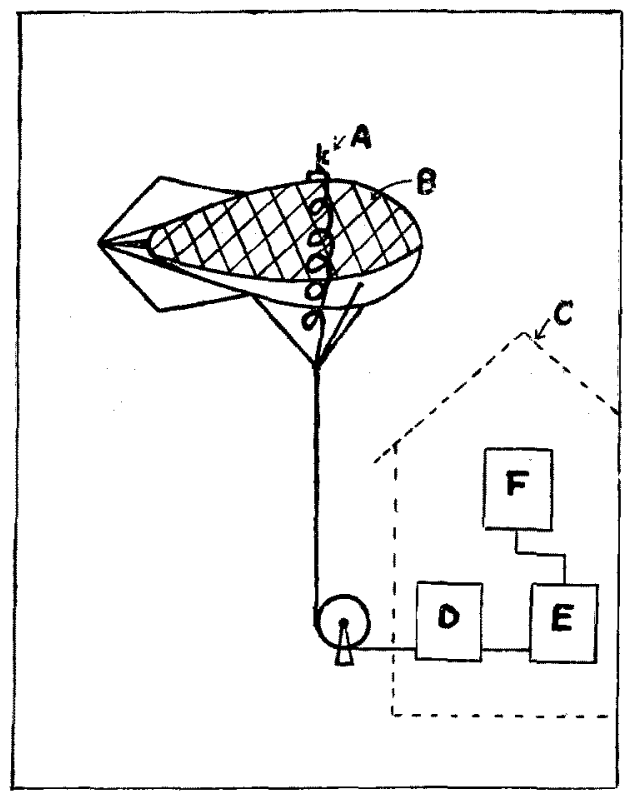

Fig. 1. Schematic diagram of the instruments for the measurements of the currents through the mooring wire. A: polonium collector, B: captive balloon sheltered with wire-nettings, $\mathrm{C}$ : observation hut, D: valve electrometer, E: amplifier, F: recording ammeter.

Fig. 1 shows the schematic diagram of the instruments for this purpose. On the upper surface of the balloon, a brass rod was set, the length of which was $15 \mathrm{~cm}$ and the diameter $5 \mathrm{~mm}$. A polonium collector was fixed near the top of the rod. The rod was insulated by an ebonite disk from the balloon. A shielded wire was used for connection between the rod and one of the four twisted wires. The other twisted wires were earthed. The surface of the balioon was sheltered with roughly meshed wire-nettings, which were connected with the earthed wires.

A wire connected with the brass rod was led to the instruments in the observation hut. The instruments consisted of a valve electrometer, an amplifier and a recorder. The circuit diagram of the valve electrometer and the amplifier are shown in Fig. 2.

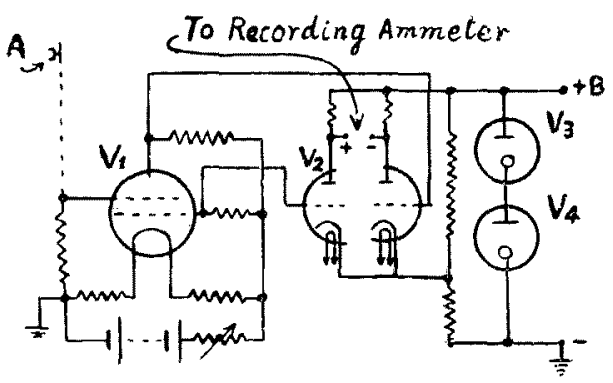

Fig. 2. Circuit diagram of the valve electrometer and the amplifier.

A: polonium collector, $V_{1}: \mathrm{UX} 54 \mathrm{~B}, V_{2}: 6 \mathrm{SN} 7, V_{3}$ : VRA135/50, $V_{4}$ :VRD90/50.

At first, instead of the brass rod a brasswire (its diameter was $1 \mathrm{~mm}$ ) was used and the collector was not attached. In such a case, the current varied according to the movement of the balloon. After the collector had been fixed, the variation of the current with the movement of the balloon diminished exceedingly, and from the fact it is considered that the collector acts as a kind of stabilizer.

The ascension of the balloon was stopped at every $30 \mathrm{~m}$ height increase, while the current was recorded for three to five minutes. In winter, the instruments were insulated satisfactorily, but when dew was deposited in summer some leakage was found and then the measured values could not be available.

The current $J$ measured in this manner may be expressed as follows:

$$
J=J_{p}+J_{d}+J_{v}+J_{c},
$$

where

$J_{p}$ is the point discharge current,

$J_{d}$ is the conduction current,

$J_{v}$ is the convection current, and 
$J_{c}$ is the current produced by the collector. After Hoffmann ${ }^{(5)}$,

$$
j_{d}=i \cdot(0.55 h)^{2} \mathrm{Amp} \text {. }
$$

where $j_{d}$ is the conduction current per unit area, $h$ is the height of the balloon and $i$ is the air-earth current per unit area. This empirical formula contains the current flowing into all parts of the mooring wire. In such a case, after Herath(6), a ratio $J / J_{d}$ is 0.057 when $h$ is $400 \mathrm{~m}$, and smaller when $h$ is less than $400 \mathrm{~m}$. In our case, the current flowing into the mooring wire may be restricted at the brass rod, and so $J_{i}$ may be neglected within the altitude of some hundred metres.

The convection current $J_{v}$ is given as follows:

$$
J_{v}=A \frac{d \rho}{d z},
$$

where $\mathrm{A}$ is the coefficient of eddy diffusion, and $d \rho / d z$ is the rate of change of space-charge with altitude.

As we know, the coefficient of eddy diffusion varies remarkably in the atmosphere. Generally $A$ in daytime is far larger than in night at the same level, especially when the nocturnal inversion exists. It may be considered that the ratio of $\mathrm{A}$ in night to that in daytime is less than $10^{-2}$ at the same altitude. The measured value of $J$ in daytime was in the order of $10^{-7}$ Amp. at $100 \mathrm{~m}$ height. As $d \rho / d z$ may be rather small at this height, $J_{v}$ in night will be below the order of $10^{-9}$ Amp. from the ground to the $100 \mathrm{~m}$ height.

As we used a collector having 0.6 ESU of saturation current, so

$$
J_{c} \leq 0.6 \times 10^{-9} \mathrm{Amp} \text {. }
$$

When the value of $J$ is more than $6 \times 10^{-9}$ Amp., the maximum error of $J$ will be ten percent even if $J_{c}$ is neglected.

Thus, when the value of the current through the mooring wire $I$ is over $6 \times 10^{-9}$ Amp., $J$ may be written approximately

$$
J=J_{p}+J_{v} \text {. }
$$

Especially when the nocturnal inversion exists,

$$
J=J_{p} .
$$

\section{(2) Measurement of the conductivity}

In order to make fit for the flying measurement on the balloon the conductivity-appara- tus was made as light as possible, and was designed so that we can make the record. reading in the observation hut on the ground. Gerdien type apparatus was adopted, in which the natural wind was utilized for the aspira. tion. An earthed cylinder was fixed outside the Gerdien-cylinder, and a valve electrometer was connected with the inner cylinder. This electrometer was shown in Fig. 2. A battery of radio-sonde was converted, so as to be used repeatedly, and was instailed in the electrometer. Its voltage was 16 Volts. The Gerdien. cylinder was made of copper and its size was as follows:

radius of the outer cylinder $\left(r_{a}\right) \quad 4 \mathrm{~cm}$ radius of the inner cylinder $\left(\boldsymbol{r}_{t}\right) \quad 1 \mathrm{~cm}$ length of the inner cylinder $(l) \quad 15 \mathrm{~cm}$ electrical capacity $(C) \quad 5.36 \mathrm{~cm}$ voltage applied to the outer cylinder $(V)$

$90 \mathrm{v}$.

The restriction by the saturation current is

$$
G>\frac{2 \kappa V l}{\left(\boldsymbol{r}_{a}^{2}-\boldsymbol{r}_{i}^{2}\right) \log \left(\boldsymbol{r}_{a} / \boldsymbol{r}_{i}\right)}
$$

where $G$ is the wind velocity in the cylinder and $\kappa$ the mobility of the small ion. If $\kappa$ is $1.5 \mathrm{~cm} / \mathrm{sec} / \mathrm{v} / \mathrm{cm}, G$ is more than $0.97 \mathrm{~m} / \mathrm{sec}$.

Fig. 3 shows the conductivity-apparatus hanged by the wire from the balloon. Four kinds of twisted mooring wires were used: two of them were for the connection between the electrometer and the amplifier in the hut, the third one for supplying the voltage to the outer cylinder, and the last one for earthing.

At first, the box which shielded the electrometer was made of aluminium, and the conductivity was measured with it on the ground. At night, the record showed the ordinary positive value, but in daytime, especially when the sun-shine was intense, the record of the positive polar conductivity crossed the zero. line and showed the negative value. When the box was interrupted from the sun-beam, the record returned to the ordinary value. It seemed to be the photoelectric effect of aluminium, and so the box was remade of paper board sheltered with earthed copper wire-nettings. In this way, the record showed the ordinary value under the exposure to the sun-beam. 
In flying the balloon, the ascension was stopped at $30 \mathrm{~m}$ intervals in height, and the conductivity was measured for some minutes at each altitude.

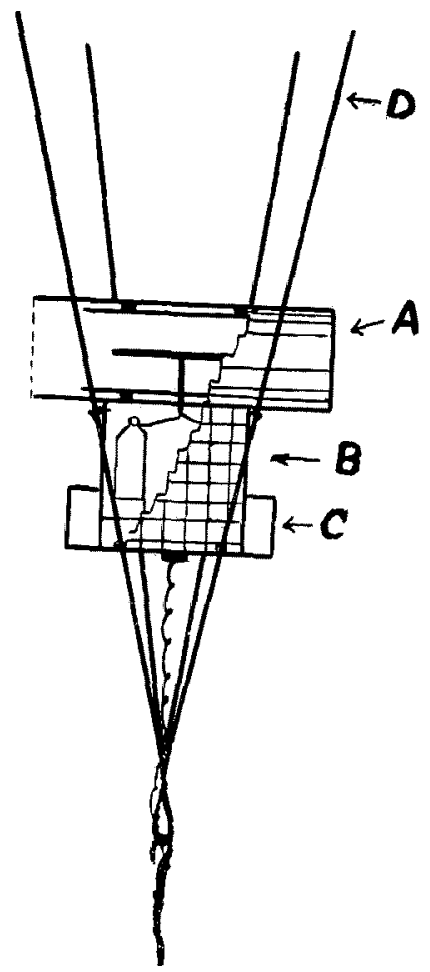

Fig. 3. Conductivity-apparatus hanged by the wire of the captive balloon. A: Gerdien-type cylinder, B: valve electrometer, C: battery, D: wire of the captive balloon.

The values of the conductivity measured in this manner should be corrected on account of the deformation of the electric field caused by the earthed mooring wire. The positive or negative polar conductivity is expressed as follows :

$$
\lambda_{ \pm}=n_{ \pm} e x,
$$

where $\lambda_{ \pm}$is the positive or negative polar conductivity, $e$ the electronic charge, and $n_{ \pm}$ the concentration of positive or negative small ion. When $e$ and $\kappa$ are constant, $\lambda_{ \pm}$is proportional to $n_{ \pm}$, and so the variations of conductivity depend on the concentration of small ions. If we assume stationary state of ionization in a given space, considering the effects of the field intensity and wind velocity, the change of ionic density may be expressed as follows: for positive small ions

$$
\begin{array}{r}
q-\alpha n_{+} n_{-}-\eta_{1} n_{+} N_{0}-\eta_{2} n_{+} N_{-} \\
-\operatorname{div} n_{+}(\kappa \boldsymbol{E}+\boldsymbol{V})=0,
\end{array}
$$

for negative small ions

$$
\begin{aligned}
q-\alpha n_{+} n_{-}-\eta_{3} n_{-} N_{0}-\eta_{4} n_{-} N_{+} \\
-\operatorname{div} n_{-}(-\kappa E+V)=0 .
\end{aligned}
$$

The term $q$ represents the rate of production of smail ions, $\alpha, \eta_{1}, \eta_{2}, \eta_{3}$ and $\eta_{4}$ are recombination coefficients, $N_{0}$ is the density of neutral nuciei and $N_{ \pm}$is positive or negative large ion density. $\quad \boldsymbol{V}$ is the wind velocity and $\boldsymbol{E}$ is the electric field intensity.

If we neglect the effect of the field, the fifth term in the left hand side of equation (9) or (10) becomes div $n_{ \pm} \boldsymbol{V}$. Assuming $\operatorname{div} \boldsymbol{V}=\mathbf{0}$, the difference between these terms is

$$
\begin{aligned}
\operatorname{div} & n_{ \pm}( \pm \kappa \boldsymbol{E}+\boldsymbol{V})-\operatorname{div} n_{ \pm} \boldsymbol{V} \\
& =\kappa \boldsymbol{E} \nabla n_{+}+\kappa n_{+} \operatorname{div} \boldsymbol{E} \text {, (for positive ions) } \\
& =-\kappa \boldsymbol{E} \nabla n_{-}-\kappa n_{-} \operatorname{div} \boldsymbol{E} \text {. (for negative ions) }
\end{aligned}
$$

When on indicates the difference between the concentration of small ions, following expressions are given:

$$
\begin{aligned}
& \delta n_{+}=\iiint \int_{0}\left(\kappa \boldsymbol{E} n_{+}+\kappa n_{+} \operatorname{div} \boldsymbol{E}\right) d x d y d z, \\
& \delta n_{-}=\iiint \int_{0}\left(-\kappa \boldsymbol{E} \boldsymbol{\nabla} n_{-}-\kappa n_{-} \operatorname{div} \boldsymbol{E}\right) d x d y d z .
\end{aligned}
$$

From equation (1), the total conductivity is

$$
\lambda_{+}+\lambda_{-}=e r\left(n_{+}+n_{-}\right) .
$$

The difference of the total conductivity between the observed value and the true value is given from (11), (12) and (13) as

$\delta\left(\lambda_{+}+\lambda_{-}\right)=e \kappa \delta\left(n_{+}+n_{-}\right)$

$=e \kappa^{2} \iiint\left\{\boldsymbol{E}\left(\boldsymbol{\nabla} n_{+}-\nabla n_{-}\right)+\operatorname{div} \boldsymbol{E}\left(n_{+}-n_{-}\right)\right\} d x d y d z$.

If we assume $n_{+}=n_{-}$, equation (14) becomes zero. So that we may say that the measured values of the total conductivity with the captive balloon equal true values, assuming $n_{+}=n_{-}$.

\section{\$3. Results of observation}

Fig. 4 shows the measured values on Feb. 28,1953 . Time is given in abscissa, altitude in ordinate, the spots show the measured points and numerals at the spots express the measured values of the wire-currents. The full lines are the contours of the wire-currents, the dotted lines are the isotherms and the chain line shows 
the heights of the maximum temperatures, above which the atmosphere is isothermal. The potential gradient at the ground surface

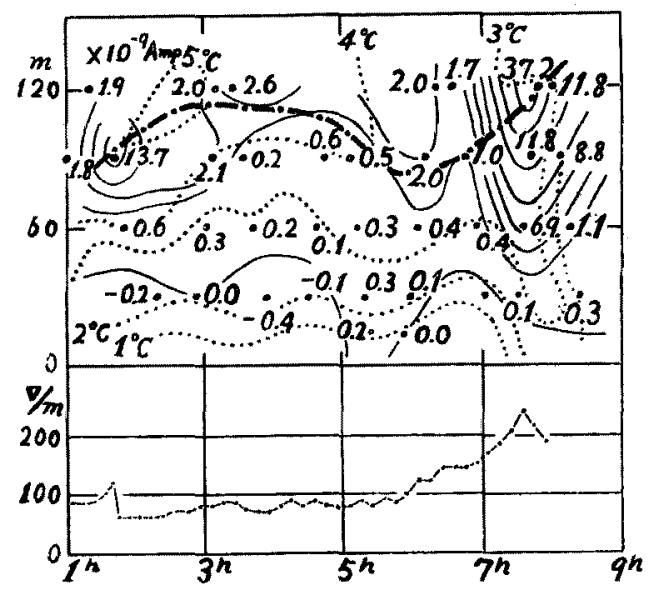

Fig. 4. Variations of the wire-currents and the potential gradients at the ground surface on Feb. $28,1953$.

_. contour of the wire-currents,

.... isotherms,

-... altitudes of the inversion.

Potential gradient at the ground surface is indicated below.

is shown in the lower part of Fig. 4. It is obvious from this figure that the maximum of the potential gradient in the morning corresponds fully to the maximum of the wirecurrent, which appears at the upper surface of the inversion layer. Figs. 5 and 6 show also the measured values on March 18, 1953 and May 21, 1953 respectively. Arrows indicate the wind directions and the wind velocities with their feathers. Each whole feather represents $1 \mathrm{~m} / \mathrm{sec}$ and half feather $0.5 \mathrm{~m} / \mathrm{sec}$. The wire-current indicates frequently a small quantity of negative values near the ground in spite of the positive field. When the earthed wirenettings were taken away from the bailoon, the values of the wire-current increased negatively, and when the balloon were sheltered with the wire-nettings, the wire-current approached to zero. Judging from this fact, it seems that the indication of the negative values depends on the charge of the balloon. The altitude of the meteorological sounding did not reach the heights of the inversion in the example shown in Fig. 5. Slight dew was deposited in nights both on the 18 th and on the 21 st, and a smail quantity of leakage was found, so that the indicated values of the wirecurrent might be a little less than true values. However, we may also find in these two figures that the increase of the potential gradient at the ground surface relates to the

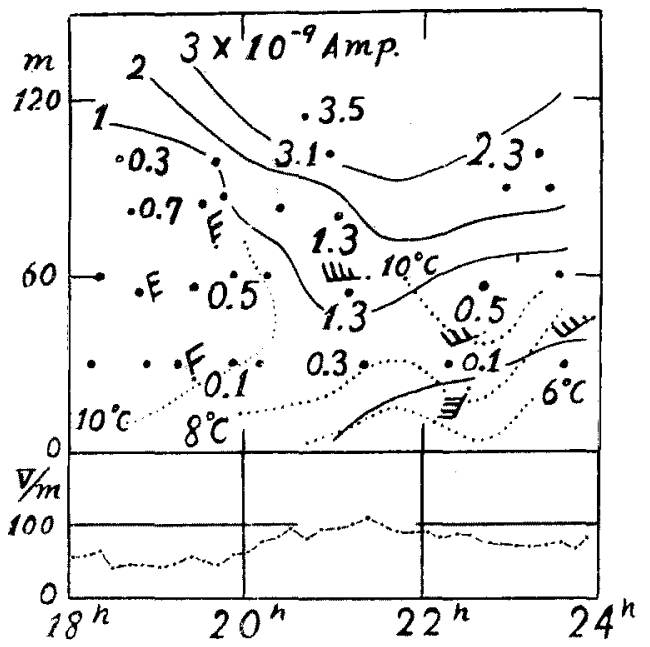

Fig. 5. Variations of the wire-current and the potential gradient at the ground surface on March 18, 1953.

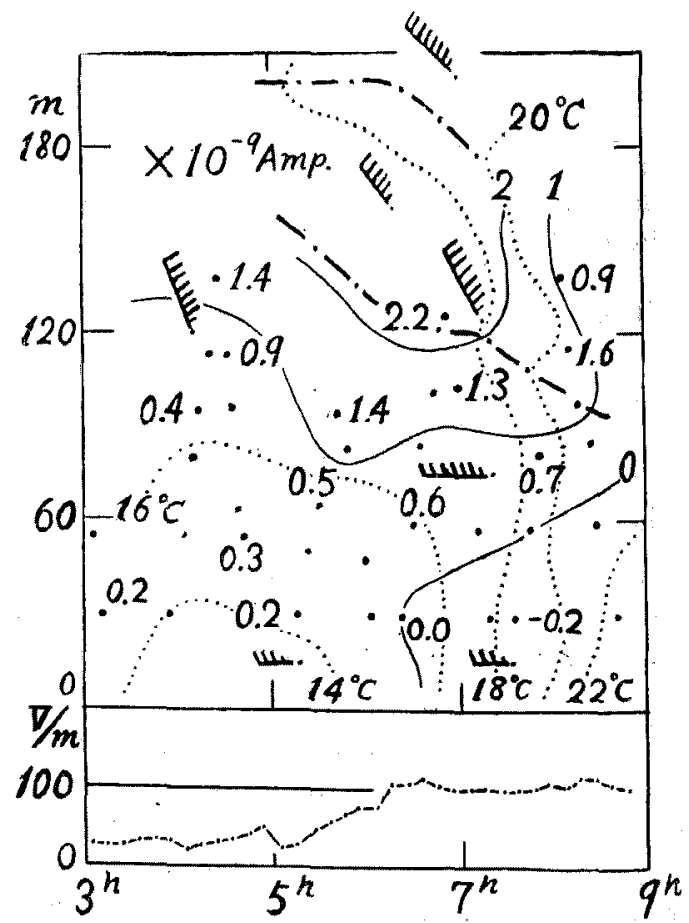

Fig. 6. Variations of the wire-current and the potential gradient at the ground surface on May $21,1953$. 
wire-current at the upper part of the inversion layer.

The variations of the wire-current below the inversion height could be found in the above indications. However, we could not find the circumstances of the wire-current in the free atmosphere above the inversion. Afterwards, we had a chance of using a greater balloon of $15 \mathrm{~m}^{3}$ and could measure the wire-current to the height of $400 \mathrm{~m}$. Fig.

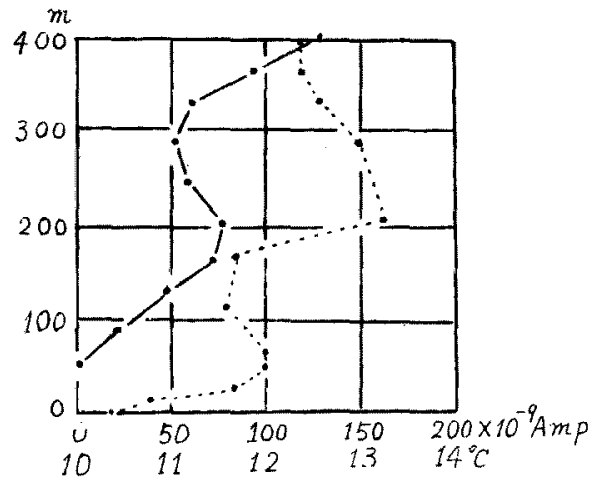

Fig. 7. Variation of the wire-current and the temperature with altitude on Oct. 7, 1953.

- wire-current,
$-\quad$ temperature.

7 shows the values of the wire-current and temperature measured on Oct. 7, 1953. The full line shows the wire-current and the dotted line the temperature. The temperature was measured from $5^{h} 21^{m}$ to $6^{h} 01^{m}$ and the wirecurrent from $6^{n} 07^{m}$ to $7^{n} 12^{m}$. The maximum of the wire-current appeared at the altitude at which the temperature indicated maximum. Above this height the wire-current slightly decreased for the thickness of $70 \mathrm{~m}$, and then, it increased again.

It is desirable to measure the conductivity and the wire-current simultaneously. How. ever, it could not be realized because of the lack of fund and hand. The measured conductivity is shown in Fig. 8. The full line shows the positive polar conductivity, the dotted line the negative, the chain line a half of the total conductivity, and the big full line indicates the temperature measured at the nearest time. The potential gradient is shown in the foot of Fig. 8. The temperature inversion did not exist and the potential gradient varied near the zero line. In such a case, the variations of the conductivity are

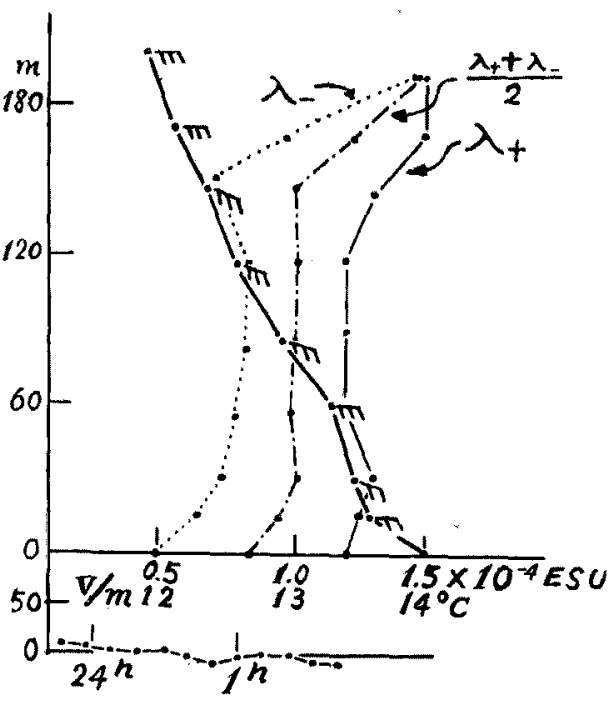

Fig. 8. Variation of the conductivity with altitude on June 9-10, 1953.

-..- positive polar conductivity, (from $23^{h} 45^{m}$ to $24^{h} 36^{m}$,

negative polar conductivity (from $0^{n} 40^{m}$ to $\left.1^{n} 39^{m n}\right)$,

half of the total conductivity,

- - temperature, (from $2^{n} 05^{m}$ to $2^{n} 42^{m}$ ).

Potential gradient at the ground surface is indicated below.

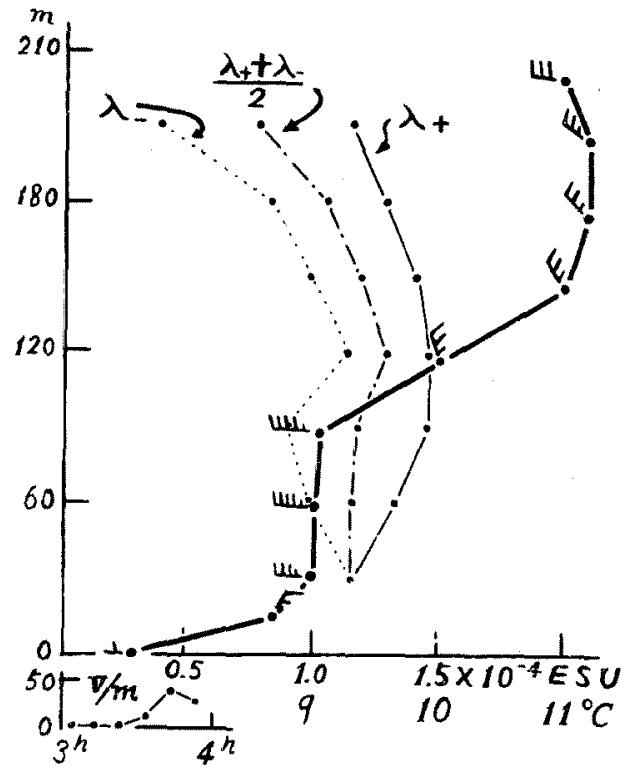

Fig. 9. Variation of the conductivity with altitude on May 5, 1953.

Positive polar conductivity was measured from $3^{h}$ $18^{m}$ to $3^{h} 33^{m}$,

negative polar conductivity was from $3^{h} 39^{m}$ to $3^{h} 53^{m}$ and temperature was from $4^{n} 11^{m}$ to $4^{h} 33^{m}$. 
comparatively small within about $150 \mathrm{~m}$ height above the ground. In Figs. 9 and 10 the

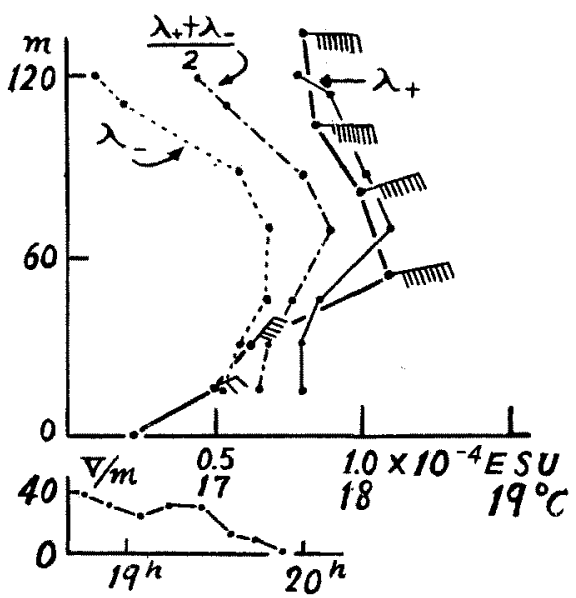

Fig. 10. Variation of the conductivity with altitude on May 20, 1953.

Positive polar conductivity was measured from $18^{h} 44^{m}$ to $19^{h} 13^{m}$,

negative polar conductivity was from $19^{n} 23^{m}$ to $19^{h} 52^{m}$ and temperature was from $20^{h} 08^{m}$ to $20^{h} 29^{m}$.

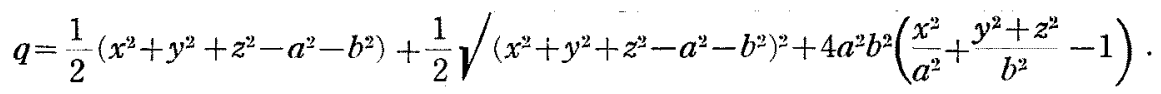

To obtain the field intensity at the top of the mooring wire, differentiate (15) with respect to $x$ and put $q=y=z=0$, then we have

$$
\left(\frac{\partial \varphi}{\partial x}\right)_{q=0}=-E_{0} \frac{\sqrt{\left(a^{2}-b^{2}\right)^{3}}}{\log \frac{a-\sqrt{a^{2}-b^{2}}+\frac{\sqrt{a^{2}-b^{2}}}{a}}{b}} \cdot \frac{2}{a^{2} b^{2}},
$$

$a \gg b$, and so

$$
\left(\frac{\partial \varphi}{\partial x}\right)_{q=0}=-E_{0} \frac{2 a}{\left(\log \frac{b}{2 a}+1\right) b^{2}} .
$$

Calculating the denominator of the equation (17), it becomes approximately constant (between $a=3 \times 10^{3}$ and $a=12 \times 10^{3}$ ), and so it may be seen that the field intensity at the top of the mooring wire is nearly proportional to the height of the balloon from $30 \mathrm{~m}$ to $120 \mathrm{~m}$.

Let us assume that the positive space charge layer exists at the upper part of the inversion, and examine the field intensity below the positive space charge layer to the ground surface, considering this layer as a oblate spheroid. We further assume that the positive space charge density $\rho$ is constant both horizontaliy and vertically.

Considering the method of image with respect to the ground surface, we obtain

$$
\begin{array}{r}
E=-\frac{8 \pi \rho a b^{2} x}{\sqrt{\left(b^{2}-a^{2}\right)^{3}}}\left\{\tan ^{-1} \frac{\sqrt{b^{2}-a^{2}}}{\left.\sqrt{a^{2}+q}-\frac{\sqrt{b^{2}-a^{2}}}{\sqrt{a^{2}+q}}\right\},}\right. \\
(a<b=c) . \quad
\end{array}
$$

If $b \gg a$, the eliipsoid may be approximated to a layer, and the equation (18) becomes

$$
E=-4 \pi \rho\left(x_{2}-x_{1}\right)
$$

where $x_{1}$ and $x_{2}$ indicate the distances from the ground surface to the lower and upper surface of the space charge layer respectively. The equation (19) denotes that the field intensity at any point between the ground surface and the lower surface of the space charge layer depends only: on the thickness of the layer. 
Now, we shall discuss the measured values on Feb. 28, 1953 (Fig. 4). The measured values of $J, V J$ and $V / J_{h} / V J_{60}$ from $7^{n} 32^{n t}$ to $7^{n} 48^{m}$ are shown in the following table:

\begin{tabular}{c|c|c|c|c|c}
\hline Height & $30 \mathrm{~m}$ & $60 \mathrm{~m}$ & $90 \mathrm{~m}$ & $120 \mathrm{~m}$ & \\
\hline$J$ & 0.1 & 6.9 & 11.8 & 37.2 & $\times 10^{-9} \mathrm{Amp}$. \\
\hline$V J$ & - & 2.63 & 3.43 & 6.11 &, \\
\hline$\sqrt{J_{h}} / V \overline{J_{60}}$ & - & 1.0 & 1.3 & 2.3 & \\
\hline
\end{tabular}

This table indicates that $\sqrt{J}$ is approximately proportional to the altitude. Considering this fact together with the equation (17), it will be understood that the wire-current is proportional to the square of the fieid intensity.

The relation between the point-discharge current $J_{p}$ and the field intensity is given as follows:

$$
J=a\left(E^{2}-M^{2}\right)
$$

where $a$ and $M$ are constants, $E$ is the external field intensity and the height of the point is constant.

In our case, the height of the point is variable, and if the external field intensity is constant, the field at the point varies proportional to the altitude of the point. It means that if we consider the height of the point is constant, the external field is variable. Consequently, we may apply the equation (20) to our case, and it is obvious that the measured current $J$ is substantially the point-discharge current. We assumed the existence of the positive space charge layer. This assumption will be sure from the fact that the maximum of the wire-current was measured at the upper surface of the inversion layer and that the total conductivity decreased above this layer.

We shall calculate the space charge density from the values on Feb. 28. Following expression will be given from the equation (19)

$$
\rho=-\frac{E}{4 \pi\left(x_{2}-x_{1}\right)} .
$$

The potential gradient at the ground is $245 \mathrm{v} /$ $\mathrm{m}$ at $7^{n} 35^{m}$ and the mean value from $2^{h}$ to $5^{h}$ is $78 \mathrm{v} / \mathrm{m}$. Putting $-E=245-78=167 \mathrm{v} / \mathrm{m}$ and $x_{2}-x_{1}=50 \mathrm{~m}$, estimating from Fig. 7, we obtain

$$
\rho=\frac{1.67}{4 \pi \times 50 \times 10^{2} \times 300}=0.09 \times 10^{-6} \mathrm{ESU} / \mathrm{cm}^{3} .
$$

\section{§. Conclusion}

Measuring the wire-current, the conductivity and simultaneous meteorological elements, the following facts may be stated:

(1) The wire-current, measured in night with our method, is substantially the pointdischarge current.

(2) The values of positive (or negative) polar conductivity, measured with the captive balloon, is generally larger (or smaller) than the true values, but assuming $\eta_{+}=\eta_{-}$, the total conductivity equals the true value.

(3) The maximum of the wire-current is measured at the upper surface of the nocturnal inversion layer, and it corresponds to the maximum of the potential gradient at the ground surface.

(4) When the inversion does not exist, the total conductivity varies scarecely within the height of about $150 \mathrm{~m}$ above the ground, but when the inversion exists, the total conductivity decreases above the inversion.

(5) Judging from (3) and (4), we may presume the existence of the positive space charge layer above the inversion.

(6) The field intensity at the top of the mooring wire is approximately proportional to the altitude of the balloon.

(7) If the distribution of the space charge extends horizontally, and its thickness is far less than its horizontal distance, the field intensity at any point between the ground surface and the bottom of this layer depends on the thickness of the layer.

(8) Calculating from the measured values, the space charge density above the inversion is about $0.1 \mathrm{ESU} / \mathrm{m}^{3}$.

Hitherto, we have been studied the local variations of the elements of atmospheric electricity in meteorological calm days, which have been thought to be least influenced on the atmospheric electricity. The local component of the potential gradient on land has its maximum in the morning, and in winter it is larger than in summer. The maximum of the potential gradient appears one or two hours later after sunrise. It is closely related 
to the fact(i) that the inversion exists still after sunrise and it needs one or two hours until the inversion disappears by the increase of the temperature from the ground surface, and that the inversion develops far greater in winter than in summer.

From the above descriptions, we may say that the potential gradient at the ground surface in so-called "calm" day is affected remarkably by the meteorological phenomenon -nocturnal inversion of the temperature--

\section{Acknow ledgement}

The writers wish to express their hearty thanks to Dr. H. Hatakeyama, Director of the Meteorological Research Institute, Mr. T. Yamaoka, Director of the Aerological Observatory, and Mr. T. Kitaoka, former Director of the Aerological Observatory, for their guidance and encouragement, and to $\mathrm{Mr}$. I. Akita for his assistance in the observations.

\section{References}

1. Nukiyama, D. and Nakata K. (1926): Proc. Phys. Math. Soc. Japan 8, 5.

2. Hatakeyama, H. and Fudimoto S. (1951): Geoph. Mag. 23, No. 1, 15.

3. Kitaoka, T. and Miyamoto, M. (1947): Journ. Aerological Observatory, Tateno, 3, 257.

4. Herath, F. (1951): Berichte d. Deutschen Wetterdienstes in d. US-Zone, Nr. 22.

5. Hoffmann, K. (1911): Diss. Techn. Hochsch., München.

6. Herath, F。 (1951): Ibid.

7. Akita, I.: To be published in Journ. Aerological Observatory, Tateno. 